\title{
Robust estimates of cuticular conductance to water on a stomatous leaf surface
}

\author{
Jun Tominaga ${ }^{1}$, Joseph Stinziano ${ }^{1}$, and David T. Hanson ${ }^{1}$ \\ ${ }^{1}$ University of New Mexico Department of Biology
}

September 25, 2021

\begin{abstract}
In leaf gas exchange measurements, cuticular conductance to water $\left(g_{c w}\right)$ is indistinguishable from and included in stomatal conductance to water vapor $\left(g_{s w}\right)$. Here we developed a simple technique to isolate $g_{c w}$ by directly measuring leaf intercellular $\mathrm{CO}_{2}$ concentration $\left(C_{i(m)}\right)$ along with gas exchange during photosynthetic light induction. We derived stomatal conductance to $\mathrm{CO}_{2}\left(g_{s c(m)}\right)$ from the $C_{i(m)}$ independently of $g_{s w}$. Plotting $g_{s w}$ against $g_{s c(m)}$ during the early induction phase within $\sim 10$ min, we found a highly linear relationship with a positive intercept. Assuming negligible cuticular $\mathrm{CO}_{2}$ transport, complete stomatal closure occurs when $g_{s c(m)}=0$. Then, we considered the residual $g_{s w}$ (i.e., intercept) as $g_{c w}$. Indeed, these $g_{c w}$ estimates succeeded in correcting the calculation. Our technique, owing to its robustness and increased throughput, will allow for more rapid screening of crops, more reliable gas exchange analysis, and more accurate prediction of plant function under natural environmental conditions.
\end{abstract}

\section{Hosted file}

MS\#1-slope method_main_PCE.docx available at https://authorea.com/users/437326/articles/ 539043-robust-estimates-of-cuticular-conductance-to-water-on-a-stomatous-leaf-surface

\section{Hosted file}

MS\#1-slope method_figures_PCE.docx available at https://authorea.com/users/437326/articles/ 539043-robust-estimates-of-cuticular-conductance-to-water-on-a-stomatous-leaf-surface 